\title{
A Numerical Modeling of Metallo-thermo-mechanical Behavior in Both Carburized and Carbonitrided Quenching Processes
}

\author{
Chuncheng LIU, Dong-Ying JU ${ }^{11}$ and Tatsuo INOUE ${ }^{2)}$ \\ High Technology Research Center, Saitama Institute of Technology, Fusaiji, Okabe, Saitama 369-0293 Japan. E-mail: liuchch@ \\ yahoo.com.cn 1) Department of Mechanical Engineering, Saitama Institute of Technology, Fusaiji, Okabe, Saitama 369- \\ 0293 Japan. E-mail: ju@sit.ac.jp $\quad$ 2) Department of Energy Conversion Science, Kyoto University, Kyoto $606-8501$ Japan. \\ E-mail: inoue@energy.kyoto-u.ac.jp
}

(Received on March 18, 2002; accepted in final form on June 25, 2002)

\begin{abstract}
A finite element modeling for the simulation of metallo-thermo-mechanical behavior and for the diffusion of carbon and nitrogen during carburized or carbonitrided quenching has been developed. In this modeling, both effects of the diffusion of carbon and nitrogen on transformation kinetics, and of the lattice expansion by the interstitial solutes on the constitutive relations of stress/strain are taken into account. Based on the modeling, prediction of carbon and nitrogen contents, microstructure and stress/distortion in cylinders after carburized or carbonitrided quenching are performed. The effects of carbon and nitrogen contents on the distributions of microstructure and residual stresses are discussed. The calculated results show a good agreement with the measured residual stresses. The agreement proves that the finite element modeling proposed in this paper is effective for numerical simulation of carburized or carbonitrided quenching.
\end{abstract}

KEY WORDS: carburized quenching; carbonitrided quenching; finite element modeling; element diffusion; metallo-thermo-mechanical behavior.

\section{Introduction}

Thermochemical processing such as carburizing or carbonitriding ${ }^{1-4)}$ is often used in the manufacturing of parts in order to improve such surface properties as resistance to fatigue, corrosion and wear. The reason for this surface modification is that advantageous changes in microstructures and distribution of residual stresses take place in the carbon (or nitrogen)-rich surface layers after carburized or carbonitrided quenching. In spite of these advantages, distortions of the treated components also occur after such kinds of processing. However, significant distortions in the parts would lead to undesirable effects, for example, distortions in gears after carburized quenching increase the noise in the transmission system. In order to control the distortion while improving properties, engineers are required to know how process parameters influence the final properties and distortions of the treated components. Therefore, a lot of experiments ${ }^{5-14)}$ have been carried out with either qualitative or quantitative analysis to some thermochemical processing. For the sake of reducing time-consuming and trial-anderror experiments that plague engineers, numerical methods are then developed to study the chemical surface treatment. One of them is to analyze the diffusion of carbon or nitrogen during carburizing or nitriding processing by finitedifference method. ${ }^{15-21)}$ The other is to predict the metallo-thermo-mechanical behavior during some heat treatment processes by several commercial FEM (Finite Element Method) codes, such as HEARTS, ${ }^{22}$ ABAQUS, ${ }^{23)}$ SYSWELD, ${ }^{24)}$ DEFORM-HT ${ }^{25)}$ and DANTE. ${ }^{26)}$ These
FEM codes also considered effect of carbon diffusion on microstructure and residual stress in carburized quenching. As a known fact, in heat treatment technologies, many chemical methods are used to improve microstructure and mechanical strength in surface of material, such as nitriding and carbon-nitriding process. However, these processes always have the complicated interactions among temperature, phase transformation, stress/strain considered with diffusion and distribution of carbon and nitrogen contents. Therefore, coupling analysis among these factors is important in order to improve the precision in simulation of heat treatment processes with chemical diffusion of carbon and nitrogen. $^{22)}$ In order to solve the problem, the numerical modeling of considered diffusion of nitrogen in nitriding or simultaneous diffusion of carbon and nitrogen in carbonitriding need to introduce into the coupling FEM analysis based on metallo-thermo-mechanical behavior.

In above mention of the study background, a main aim of this paper is to propose a numerical modeling for carburized or carbonitrided quenching. This modeling is used to predict residual stress and distortion, temperature field, microstructure distribution as well as carbon and nitrogen contents. Using this modeling, numerical simulations both carburized quenching and carbonitrided quenching for a cylinder of carbon steel are performed. In order to verify the proposed modeling, the simulated results of the cylinder are then discussed and compared with the measured cooling curves, residual stresses and hardness in the cylinder. The difference of thermomechanical and thermochemical behaviors in both carburized quenching and carbonnitrded 
quenching also is discussed in the paper.

\section{Numerical Simulation Models}

The present paper motivates to quantitatively describe metallo-thermo-mechanical behavior during carburized or carbonitrided quenching by numerical simulation, and to obtain the data on evolutions of temperature field, microstructure distribution, composition profiles and stress/ distortion. However, complicated interactions exist among these fields as illustrated in Fig. 1 schematically, which is the more general case of simple metallo-thermo-mechanical coupling in the previous literature. ${ }^{22,27)}$

As is well known, temperature gradient due to cooling induces a thermal stress (1). Temperature-dependent phase transformation (2) leads to the change of microstructure in a solid. Local expansion due to phase change brings about transformation stress (3) and the effect of transformation plasticity also contributes to the stress/strain field in the solid. The existing stress and strain influence the kinetics of phase transformation, known as stress/strain-induced transformation or mechanical stabilization (4). Latent heat generation (5) due to phase transformation affects the temperature distribution. Part of mechanical work done by existing stress converts into heat generation (6), which disturbs the temperature field. The effects of diffusion of $\mathrm{C} / \mathrm{N}$ (carbon and nitrogen) on phase transformation, corresponding to Arrow number (7), are reflected through two mechanisms: One is that increments of $\mathrm{C} / \mathrm{N}$ contents postpone phase transformation to a lower temperature range for both diffusive and displacive transformation; and the other is that carbides and nitrides are to be formed in the surface layer of the solid once the contents of $\mathrm{C} / \mathrm{N}$ there exceed their saturation limits in the matrix. Both of them are discussed in the Sec. 2.2 of this paper. Diffusion kinetics of $\mathrm{C} / \mathrm{N}$ in materials and surface reaction rates of $\mathrm{C} / \mathrm{N}$ depend on microstructure morphology (8) and temperature levels (9). In addition, arrow number (10) corresponds to the influences of $\mathrm{C} / \mathrm{N}$ contents on the thermal conductivity properties of the materials. Absorption of $\mathrm{C} / \mathrm{N}$ atoms from atmosphere gas sources leads to the changes of lattice parameters, which should be taken into account when establishing the constitutive equations of stress and strain (11). Arrow number (12) means the possible effects of stress/strain fields on diffusion kinetics of $\mathrm{C} / \mathrm{N}$, an undetermined question up to now. In addition, interactions exist between diffusion of carbon and that of nitrogen, ${ }^{28)}$ corresponding to arrows (13) and (14), which is also an interesting subject for experiments and modeling.

The descriptions above, is improvement form of metallothermo-mechanical theory considered with diffusion of carbon/nitrogen. The next part summarizes the governing ${ }^{27)}$ equations for temperature, diffusion, microstructure and stress/strain which are necessary for numerical simulation of carburized or carbonitrided quenching.

\subsection{Heat Conduction}

Heat conduction equation with heat generation from plastic work and latent heat $L_{I}$ due to phase transformation from parent phase to the $I$-th phase governs temperature field $T$ by

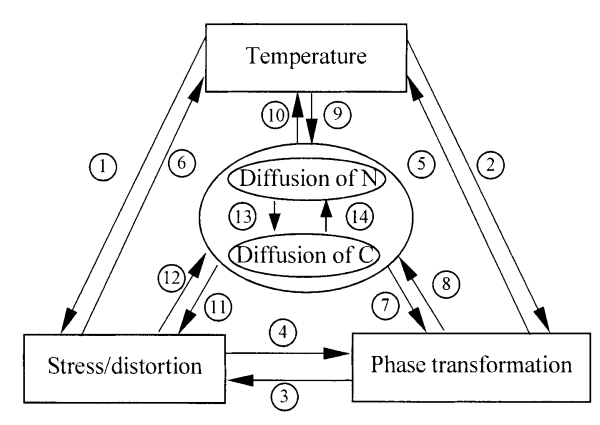

Fig. 1. A schematic illustration of metallo-thermo-mechanical coupling during processes involving phase transformation and diffusion of carbon and nitrogen.

$$
\rho c \dot{T}-\frac{\partial}{\partial x_{i}}\left(k \frac{\partial T}{\partial x_{i}}\right)-\sigma_{i j} \dot{\varepsilon}_{i j}^{\mathrm{p}}-\rho \sum_{I} L_{I} \dot{\xi}_{I}-r_{\mathrm{v}}=0
$$

with heat transfer boundary condition

$$
-k \frac{\partial T}{\partial x_{i}} n_{i}=h(T)\left(T-T_{\mathrm{w}}\right)
$$

where $\sigma_{i j}$ is stress tensor, $\dot{\varepsilon}_{i j}^{\mathrm{p}}$ means plastic strain rate, and $\rho, c$ and $k$ respectively denote density, specific heat and heat conductivity, depending on temperature $T$, contents of carbon/nitrogen as well as volume fraction $\xi_{I}$ of each phase. $r_{\mathrm{v}}$ is internal heat source, $h(T)$ is a heat transfer coefficient dependent on temperature, $T_{\mathrm{w}}$ means environmental temperature on the boundary with the unit normal $n_{i}$. Values of $\rho, c$ and $k$ are evaluated through mixture rule $X=\sum_{I} X_{I} \xi_{I}$, where $X$ and $X_{I}$ are properties of bulk material and the $I$-th constituent, respectively.

\subsection{Diffusion of Nitrogen and Carbon}

The equation describing diffusion field of nitrogen is

$$
\dot{N}-\frac{\partial}{\partial x_{i}}\left(D_{\mathrm{N}} \frac{\partial N}{\partial x_{i}}\right)=0,
$$

with boundary condition

$$
-D_{\mathrm{N}} \frac{\partial N}{\partial x_{i}} n_{i}=\beta_{\mathrm{N}}\left(N-N_{\mathrm{w}}\right)
$$

where $N$ and $N_{\text {w }}$ are, respectively, nitrogen concentration in position $x_{i}$ and environment chemical potential (both in mass $\%$ ), and $\beta_{\mathrm{N}}$ is the surface reaction rate coefficient. Global diffusivity, $D_{\mathrm{N}}$, is obtained by the mixture law of each constituent according to the following formula

$$
D_{\mathrm{N}}=\sum_{I} D_{\mathrm{N} I, 0} f(C, N) h(\operatorname{grad} C, \operatorname{grad} N) \exp \left(-\frac{Q_{\mathrm{N}}}{R T}\right) \xi_{I},
$$

where $f(C, N)$ is a function of the concentrations of carbon and nitrogen, $h(\operatorname{grad} C, \operatorname{grad} N)$ is a function of the gradients of carbon and nitrogen, $Q_{\mathrm{N}}$ is the activation energy for diffusing nitrogen, and $D_{\mathrm{N} I, 0}$ and $R$ are material constants. The coefficient of surface reaction rate $\beta_{\mathrm{N}}$ is given by 


$$
\beta_{\mathrm{N}}=\beta_{0} p_{\mathrm{H}_{2}} \exp \left(-\frac{Q_{\mathrm{N}}}{R T}\right),
$$

where $\beta_{0}$ is a constant and $p_{\mathrm{H}_{2}}$ is partial pressure of hydrogen in the mixed gas. ${ }^{29)}$

The equation governing diffusion kinetics of carbon can be simply obtained by replacing $N$ with $C$ in Eq. (3), as shown by

$$
\dot{C}-\frac{\partial}{\partial x_{i}}\left(D_{\mathrm{C}} \frac{\partial C}{\partial x_{i}}\right)=0,
$$

with the following boundary condition

$$
-D_{\mathrm{C}} \frac{\partial C}{\partial x_{i}} n_{i}=\beta_{\mathrm{C}}\left(C-C_{\mathrm{W}}\right),
$$

where surface reaction rate coefficient $\beta_{\mathrm{C}}$ for carburizing is determined according to the method by Ishigami et al. ${ }^{30)}$

\subsection{Phase Transformation Kinetics}

The microstructures concerned in the quenching process are assumed to be composed of three constituents: austenite, pearlite or bainite and martensite. Decomposition of austenite into pearlite is governed by the modified JohnsonMehl relation. ${ }^{31,32)}$ The volume fraction of pearlite $\xi_{\mathrm{p}}$ is expressed depending on mean stress $\sigma_{\mathrm{m}}$ such that

$$
\begin{aligned}
& \xi_{\mathrm{p}}=1-\exp \left\{-\int_{0}^{t} f_{1}(T) f_{2}(C, N) f_{3}(\sigma)(t-\tau)^{3} d \tau\right\}, \\
& f_{1}(T)=a_{0}\left(\frac{T-a_{1}}{a_{2}}\right)^{a_{3}}\left(\frac{a_{4}-T}{a_{5}}\right)^{a_{6}} \\
& f_{2}(C, N)=\exp \left\{-a_{7}\left(C-C_{0}\right)-a_{\mathrm{s}}\left(N-N_{0}\right)\right\}, \\
& f_{3}(\sigma)=\exp \left(a_{9} \sigma_{\mathrm{m}}\right),
\end{aligned}
$$

where $C$ and $C_{0}$ denote current and initial contents (in mass \%) of carbon, $N$ and $N_{0}$ are those of nitrogen, and $a_{i}$ $(i=0,1,2, \cdots, 9)$ are material parameters. Displacive transformation into martensite is controlled by modified Magee's rule ${ }^{33)}$ considering the effects of mean stress $\sigma_{\mathrm{m}}$ and equivalent stress $\sigma_{\mathrm{e}}$

$$
\begin{aligned}
\xi_{\mathrm{M}}= & 1-\exp \left\{\phi_{1} T+\phi_{2}\left(C-C_{0}\right)\right. \\
& \left.+\phi_{3}\left(N-N_{0}\right)+\phi_{4} \sigma_{\mathrm{m}}+\phi_{5} \sigma_{\mathrm{e}}+\phi_{6}\right\},
\end{aligned}
$$

where $\xi_{\mathrm{M}}$ is the volume fraction of martensite, and $\phi_{i}$ $(i=1,2, \cdots, 6)$ are material parameters. Descriptions of the governing equations above involve the effects of $\mathrm{C} / \mathrm{N}$ contents on diffusive and displacive transformation kinetics during quenching. However, the diffusion of carbon or nitrogen from outside gas source into surface layer may lead to other kinds of transformation - precipitation of carbides or nitrides.

As observed in the $\mathrm{Fe}-\mathrm{N}$ phase diagram shown in Fig. $2,{ }^{34)}$ new phases $\left(\gamma^{\prime}-\mathrm{Fe}_{4} \mathrm{~N}\right.$ or $\left.\varepsilon-\mathrm{Fe}_{2} \mathrm{~N}\right)$ will appear with increasing nitrogen content even when the temperature remains constant. Figure 3 presents an example of the growth of nitrides $\left(\gamma^{\prime}-\mathrm{Fe}_{4} \mathrm{~N}\right.$ and $\left.\varepsilon-\mathrm{Fe}_{2} \mathrm{~N}\right)$ into substrate $\alpha$-Fe when nitriding below $593^{\circ} \mathrm{C}$. With nitriding time, when the nitro-

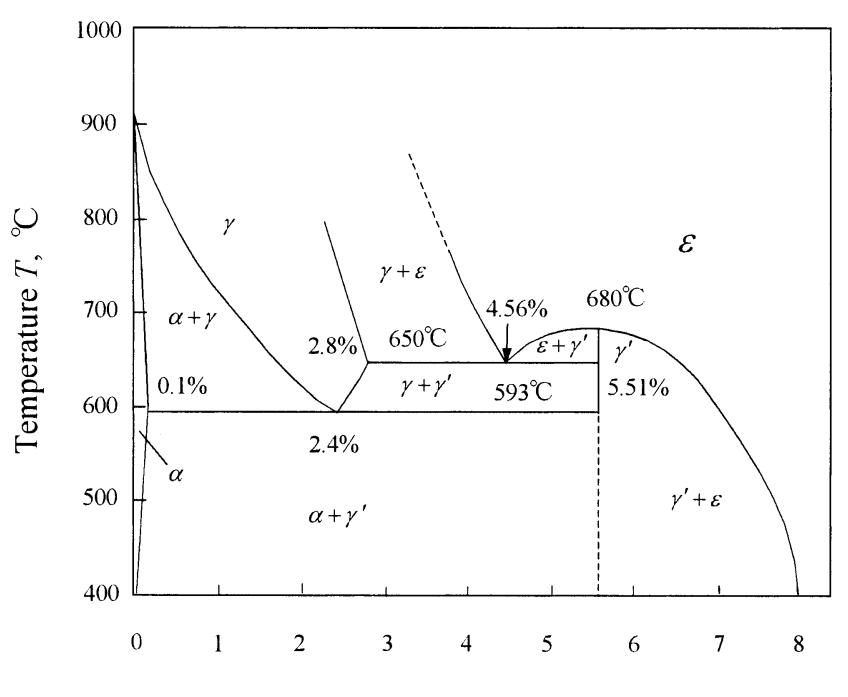

Nitrogen content $N$, mass $\%$

Fig. 2. A part of phase diagram of $\mathrm{Fe}-\mathrm{N} .{ }^{34)}$

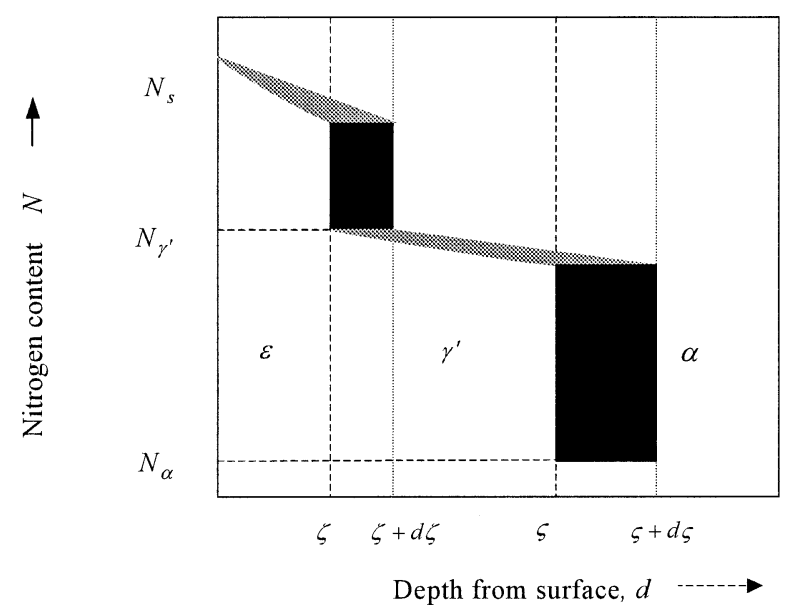

Fig. 3. Schematic diagram for growth of new phases during nitriding.

gen content $N_{\mathrm{s}}$ on the surface reaches the solubility limit $N_{\alpha}$ of nitrogen in the matrix $\alpha$-Fe, nitride $\gamma^{\prime}-\mathrm{Fe}_{4} \mathrm{~N}$ is initiated in the surface. After certain time, because of continuous diffusion of nitrogen into deeper layer, $\gamma^{\prime}-\mathrm{Fe}_{4} \mathrm{~N}$ is formed in the depth position $\zeta$ and compound layer of $\gamma^{\prime}-\mathrm{Fe}_{4} \mathrm{~N}$ with depth $\varsigma$ is formed. During the same time, the nitrogen content in the surface will increase continuously, and nitrogen content in $\gamma^{\prime}-\mathrm{Fe}_{4} \mathrm{~N}$ formed earlier also increases $\left(N_{\gamma^{\prime}}\right.$ is the maximum content of nitrogen in $\left.\gamma^{\prime}-\mathrm{Fe}_{4} \mathrm{~N}\right)$. Once the nitrogen distributions in the surface compound layer of $\gamma^{\prime}-\mathrm{Fe}_{4} \mathrm{~N}$ meet the conditions for formation of $\varepsilon-\mathrm{Fe}_{2} \mathrm{~N}$, nitride $\varepsilon-\mathrm{Fe}_{2} \mathrm{~N}$ then precipitates accompanied by the disappearance of $\gamma^{\prime}$ $\mathrm{Fe}_{4} \mathrm{~N}$. Within a given time, the interface between $\varepsilon-\mathrm{Fe}_{2} \mathrm{~N}$ and $\gamma^{\prime}-\mathrm{Fe}_{4} \mathrm{~N}$ arrives the position $\zeta$. After that, with time increment $d t$, interfaces of $\varepsilon / \gamma^{\prime}$ and $\gamma^{\prime} / \alpha$ respectively shift $d \zeta$ and $d \varsigma$ toward inner layer. The shifting rates of the interfaces depend on the diffusion kinetics of nitrogen in the involved compounds and substrate. ${ }^{3,35,36)}$ The precipitation kinetics of the two iron nitrides can be calculated based on the assumption of local thermodynamic equilibrium. ${ }^{17,37)}$ If nitriding temperature is in the range between $593^{\circ} \mathrm{C}$ and $680^{\circ} \mathrm{C}$, more complicated interfaces $\left(\alpha / \gamma, \gamma / \gamma^{\prime}, \gamma / \varepsilon\right.$ or $\left.\gamma^{\prime} / \varepsilon\right)$ 
are involved ${ }^{2)}$ which is to be solved in the future.

As a known fact, the appearance of carbides or nitrides accompanies the change of lattice parameters, ${ }^{8,38)}$ which contributes to the variation of internal stresses. This should also be taken into account when modeling the evolution of internal stresses.

\subsection{Constitutive Equations}

Total strain rate $\dot{\varepsilon}_{i j}$ is assumed to be the sum of rates of elastic strain $\dot{\varepsilon}_{i j}^{\mathrm{e}}$, plastic strain $\dot{\varepsilon}_{i j}^{\mathrm{p}}$, thermal strain $\dot{\varepsilon}_{i j}^{\text {th }}$, transformation strain $\dot{\varepsilon}_{i j}^{\text {tr }}$, transformation plasticity strain $\dot{\varepsilon}_{i j}^{\text {tp }}$ and diffusion-induced strain $\dot{\varepsilon}_{i j}^{\mathrm{df}}$ of carbon and nitrogen:

$$
\dot{\varepsilon}_{i j}=\dot{\varepsilon}_{i j}^{\mathrm{e}}+\dot{\varepsilon}_{i j}^{\mathrm{p}}+\dot{\varepsilon}_{i j}^{\mathrm{th}}+\dot{\varepsilon}_{i j}^{\mathrm{tr}}+\dot{\varepsilon}_{i j}^{\mathrm{tp}}+\dot{\varepsilon}_{i j}^{\mathrm{df}}
$$

Here the elastic strain and plastic strain rate are expressed by

$$
\begin{array}{r}
\varepsilon_{i j}^{\mathrm{e}}=\frac{1+v}{E} \sigma_{i j}-\frac{v}{E} \sigma_{k k} \delta_{i j}, \ldots \ldots \ldots \ldots \ldots . . . . . . . \\
\dot{\varepsilon}_{i j}^{\mathrm{p}}=\hat{G}\left\{\frac{\partial F}{\partial \sigma_{k l}} \sigma_{k l}+\frac{\partial F}{\partial T} \dot{T}+\sum_{I=1}^{K} \frac{\partial F}{\partial \xi_{I}} \dot{\xi}_{I}\right\} \frac{\partial F}{\partial \sigma_{i j}}, \ldots . . \\
\frac{1}{\hat{G}}=-\left(\frac{\partial F}{\partial \varepsilon_{m n}^{\mathrm{p}}}+\frac{\partial F}{\partial \kappa} \sigma_{m n}\right) \frac{\partial F}{\partial \sigma_{m n}}, \ldots \ldots \ldots . . .
\end{array}
$$

with temperature and microstructure dependent yield function

$$
F=F\left(\sigma_{i j}, \varepsilon_{i j}^{\mathrm{p}}, \kappa, T, \xi_{I}\right),
$$

where, $E$ and $v$ are Young's modulus and Poisson's ratio, $\kappa$ is a hardening factor, and $T$ is temperature. The other three terms are expressed as

$$
\begin{array}{r}
\dot{\varepsilon}_{i j}^{\mathrm{th}}=\sum_{I=1}^{K} \alpha_{I} \dot{T} \delta_{i j}, \ldots \ldots . \\
\dot{\varepsilon}_{i j}^{\mathrm{tr}}=\sum_{I=1}^{K} \beta_{I} \dot{\xi}_{I} \delta_{i j}, \ldots \ldots . \\
\dot{\varepsilon}_{i j}^{\mathrm{tp}}=\sum_{I=1}^{K} 3 K_{I}\left(1-\xi_{I}\right) s_{i j} \dot{\xi}_{I},
\end{array}
$$

where $\beta_{I}$ and $K_{I}$ denote transformation expansion coefficient and transformation plasticity parameter depending on the producing of $I$-th phase, respectively, $\alpha_{I}$ means thermal expansion coefficient of the $I$-th phase, and $s_{i j}$ is deviatoric stress tensor.

Compared with the previous constitutive equations ${ }^{22)}$ of the authors, a new term $\dot{\varepsilon}_{i j}^{\text {df }}$ in Eq. (14) due to diffusion of carbon or nitrogen is introduced in this paper. When carbon or nitrogen is absorbed as interstitial atoms, changes of lattice parameters lead to volumetric dilatation or extraction. Earlier researchers ${ }^{38)}$ proposed some formulae of the lattice parameters depending on carbon and nitrogen contents. If transformation $(\alpha \rightarrow \beta)$ occurs between the interval from the time $t_{0}$ to $t_{1}$ due to the diffusion of carbon and nitrogen, the strain $\dot{\varepsilon}_{i j}^{\mathrm{df}}$ is

$$
\dot{\varepsilon}_{i j}^{\mathrm{df}}=\frac{1}{3}\left(\frac{V_{\beta}^{\mathrm{T}}\left(C_{t_{1}}, N_{t_{1}}\right) / n_{\beta, \mathrm{Fe}}}{V_{\alpha}^{\mathrm{T}}\left(C_{t_{0}}, N_{t_{0}}\right) / n_{\alpha, \mathrm{Fe}}}-1\right) \dot{\xi}_{\alpha \rightarrow \beta} \delta_{i j} \ldots \ldots
$$

where $n_{I, \mathrm{Fe}}$ means the number of Fe atoms in single unit cell of certain microstructure. $V_{\alpha}^{\mathrm{T}}$ and $V_{\beta}^{\mathrm{T}}$ denote the volume of lattice before and after $\alpha \rightarrow \beta$ transformation, while $C_{t_{1}}$ and $N_{t_{1}}$ are, respectively, the carbon and nitrogen contents (in mass $\%$ ) at time $t_{1}, C_{t_{0}}$ and $N_{t_{0}}$ are those at time $t_{0}$.

The value of $V_{I}^{\mathrm{T}}$ varies depending on the lattice type of the $I$-th phase, as shown in the equation

$$
\left.V_{I}^{\mathrm{T}}(C, N)\right|_{I=\alpha, m, \gamma}= \begin{cases}a^{3} f(T) & \text { for fcc } \\ a^{2} c f(T) & \text { for } \mathrm{fcc}\end{cases}
$$

where $a$ and $c$ are lattice parameters of fcc or bcc lattice, $f(T)$ is a function of temperature. The lattice parameters of austenite, ferrite and martensite phase are determined as the following formulae, ${ }^{8,38)}$ depending on the contents of nitrogen $X_{\mathrm{N}}$ and carbon $X_{\mathrm{C}}$ (in atom $\%$ ).

Austenite lattice parameter:

$$
a=0.3573+0.00080 X_{N}+0.00075 X_{\mathrm{C}} \quad\left(\text { in } 10^{-9} \mathrm{~m}\right) .
$$

Martensite lattice parameters:

$$
\begin{array}{ll}
a=0.28664+0.00018 X_{N}-0.00028 X_{\mathrm{C}} & \left(\text { in } 10^{-9} \mathrm{~m}\right), \ldots . \\
c=0.28664+0.00263 X_{N}+0.00256 X_{\mathrm{C}} & \left(\text { in } 10^{-9} \mathrm{~m}\right) \ldots . .
\end{array}
$$

Ferrite lattice parameter:

$$
a=0.28664 \quad\left(\text { in } 10^{-9} \mathrm{~m}\right) .
$$

If no transformation occurs during diffusion of carbon or nitrogen, the microstructure is simply composed of single lattice structure. For thermo-chemical processing in the austenite temperature range, the strain rate $\dot{\varepsilon}_{i j}^{\mathrm{df}}$ depends on the diffusion rate of carbon and nitrogen in the form:

$$
\dot{\varepsilon}_{i j}^{\mathrm{df}}=\frac{1}{3}\left\{\frac{a^{3}\left(C_{t_{1}}, N_{t_{1}}\right)}{a^{3}\left(C_{t_{0}}, N_{t_{0}}\right)}-1\right\}\left(\frac{1}{C_{t_{1}}-C_{t_{0}}} \dot{C}+\frac{1}{N_{t_{1}}-N_{t_{0}}} \dot{N}\right) \delta_{i j},
$$

where lattice parameter $a$ is a function of carbon and nitrogen contents (see Eqs. (23) through (26)).

Based on the theories above, a software tool was developed for numerical simulation of carburized or carbonitrided quenching. The simplified flow chart of the whole simulation procedure is illustrated in Fig. 4. At present, the complicated interactions between $\mathrm{C}$ and $\mathrm{N}$ profiles are ignored because of lack of necessary data used in Eq. (5).

\section{Materials, Experiments and Simulation}

The steel used in this study is a carbon steel S45C (Fe$0.45 \mathrm{mass} \% \mathrm{C}$ ). Figure 5(a) shows the heat pattern of carbonitrided quenching (marked by $\mathrm{C} 3 \mathrm{~N} 3$ in later text). In the first step, the specimen is heated up to $860^{\circ} \mathrm{C}$ from room temperature and then mixed gas is provided with a carbon potential $(0.9$ mass $\%)$ and a nitrogen potential $(0.9$ mass $\%)$, respectively. Then the specimen is to be carbonitrided for $16200 \mathrm{~s}$. After that, the specimen is cooled to $850^{\circ} \mathrm{C}$ by $1^{\circ} \mathrm{C} / \mathrm{min}$ and then is held at the temperature for $1800 \mathrm{~s}$ as a 


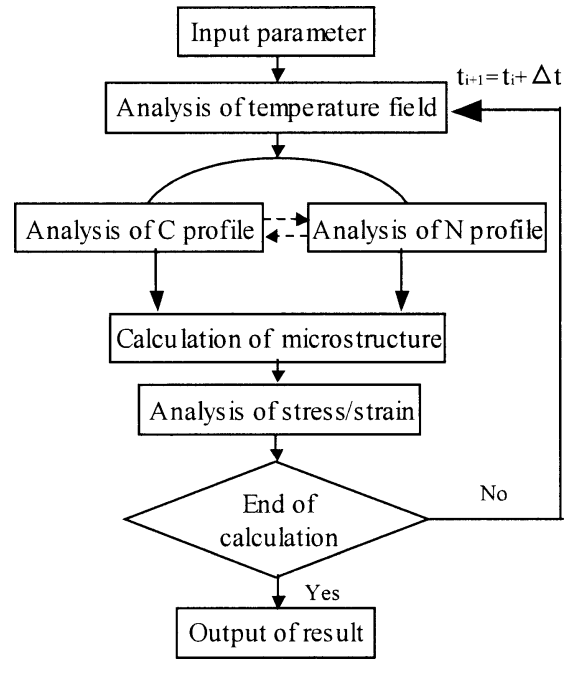

Fig. 4. Flow chart of simulation.

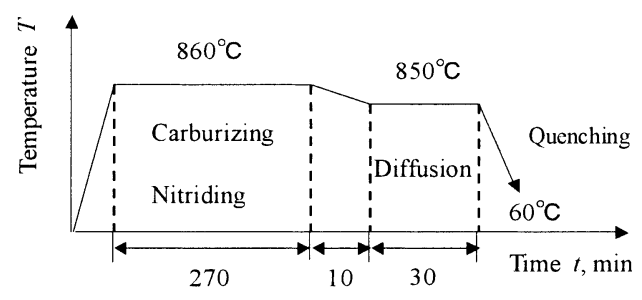

(a) Carbonitrided quenching (C3N3)

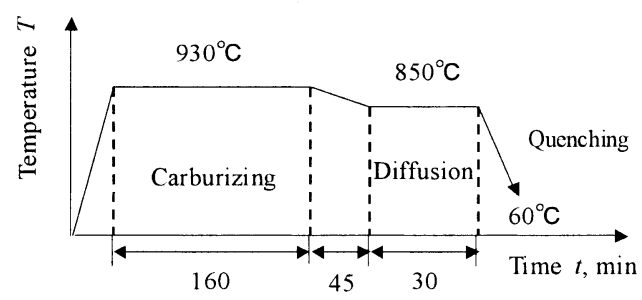

(b) Carburized quenching (C3N0)

Fig. 5. Heat patterns for carbonitrided quenching (a) and carburized quenching (b).

diffusion period to decrease the gradients of carbon and nitrogen in the specimen. Finally, the specimen is cooled by oil quenchant of $60^{\circ} \mathrm{C}$. The process for carburized quenching (Fig. 5(b), marked by C3N0 in later text) is similar to that of carbonitrided quenching only with the variation of processing time and without nitrogen potential. Figure 6(a) shows the configuration of the cylindrical specimens used to perform the experiments of carburized and carbonitrided quenching. Two holes with diameter of $1 \mathrm{~mm}$ were drilled in the specimens to insert thermocouples for measurement of cooling curves on the both measured points. After these experiments, hardness $\mathrm{H}_{v}$, residual stresses on the surface of cylinder and the changes of cylinder diameter were measured.

The mesh division of the axisymmetrical model for numerical calculation is depicted as shown in Fig. 6(b). Due to the symmetry, one-fourth of the specimen is employed for meshing by quadrilateral iso-parameter elements. The thermal and diffusion boundary conditions in the side sur-

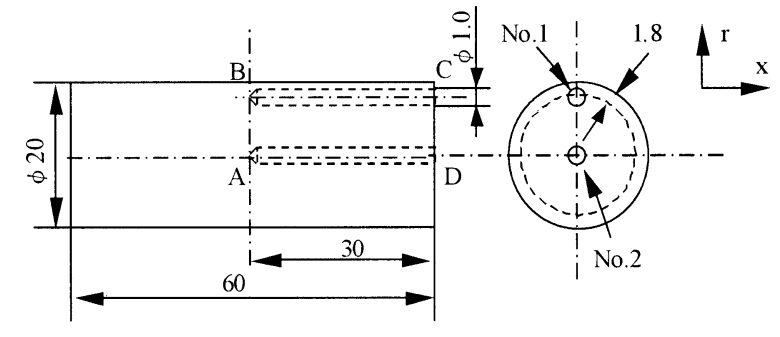

(a) Configuration of the specimen, $\mathrm{mm}$

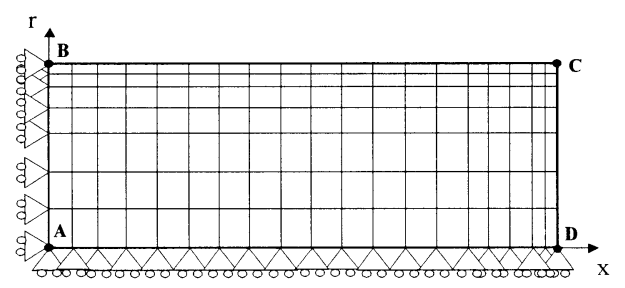

(b) FE mesh

Fig. 6. Configuration of specimen (a) and FE mesh (b).

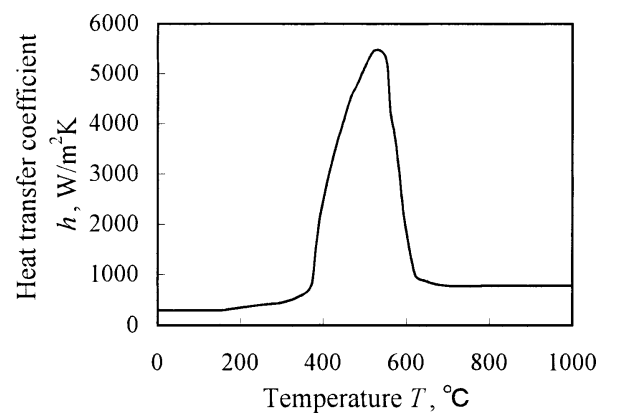

Fig. 7. Variation of heat transfer coefficient between oil and specimen.

face $\mathrm{BC}$ and end surface $\mathrm{CD}$ are both flux type. The heat transfer coefficient (Fig. 7) between oil and specimen is represented with a function of temperature resulted from inverse calculation based on the measured temperature curves. ${ }^{32)}$ Then the variation of temperature, carbon or nitrogen contents, phase transformation, stress/strain and distortion during the both carburized quenching and carbonnitrided quenching are simulated.

\section{Results and Discussion}

\subsection{Prediction of Carbon and Nitrogen Contents}

Figures 8(a) and 8(b) show the calculated carbon and nitrogen distributions in the surface BC, respectively. Higher contents of carbon and nitrogen near the position $\mathrm{C}$ result from the penetration of carbon and nitrogen from end surface $\mathrm{CD}$. The carbon contents after carburized quenching (C3N0) are lower than those after carbonitrided quenching (C3N3). The reason may be a shorter carburizing time in the former.

Figure 9 demonstrates the calculated carbon and nitrogen contents in the middle section $\mathrm{AB}$ corresponding to various diffusing time for the carburizing and carbonitriding cases. During the whole procedure, the contents of carbon and nitrogen in the shallow layer near position B first 


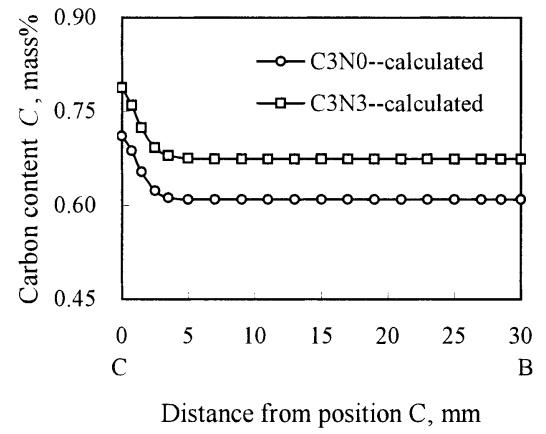

(a) Calculated carbon content

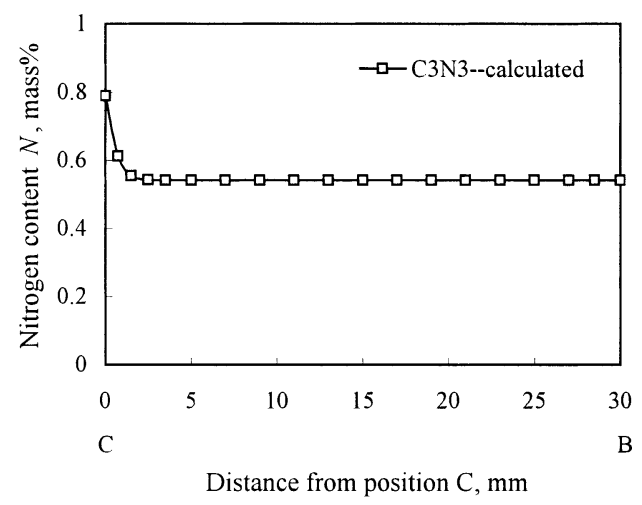

(b) Calculated nitrogen content

Fig. 8. Prediction of carbon (a) and nitrogen (b) contents on the line $\mathrm{BC}$.

increase and then decrease in the diffusion stage. On the other hand, contents of carbon and nitrogen in the deeper layer far from position B increase all along in the entire processing since carbon or nitrogen is continuously diffused to the deeper layer. As a final result, distributions of carbon and nitrogen in the penetration layer tend to take on an "S" shape with carbon and nitrogen platforms in the shallow layer near the surface position B. This kind of distribution is said to be advantageous for components to avoid fatigue in the early service stage due to the steep gradients of carbon and nitrogen in the penetration layer. ${ }^{39)}$ In addition, such distributions of carbon and nitrogen contents as shown in Figs. 8 and 9 have great effects on the followed phase transformation and stress.

\subsection{Hardness and Microstructure}

Hardness values of a quenched specimen depend on the morphology and fraction of microstructure and the content of carbon. Figure 10 represents the Vickers hardness values in the surface layer of the middle section AB. The hardness values decrease with increasing the depth from the surface position $\mathrm{B}$, irrespective carburized or carbonitrided quenching. The results reflect on the carburizing or carbonitriding, as shown in Fig. 9. According to the transformation kinetics shown by Eqs. (9) through (13), higher carbon and nitrogen contents not only hinder the decomposition of austenite to the relatively soft phase-pearlite, but also postpone the decomposition of austenite to martensite into a lower temperature range. Figure 11 displays that martensite transformation during carburized quenching $(\mathrm{C} 3 \mathrm{~N} 0)$ or carbonitrided

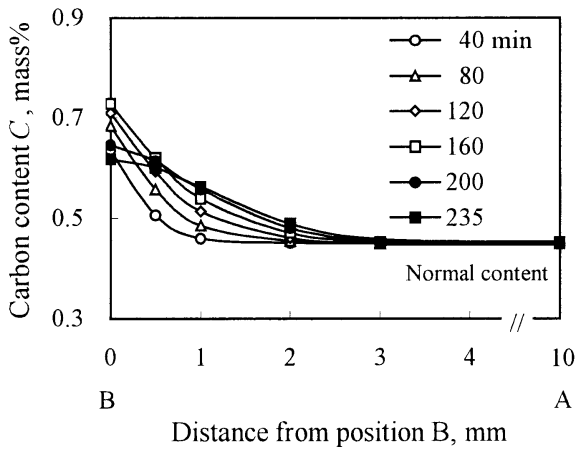

(a) Carbon content for carburized quenching

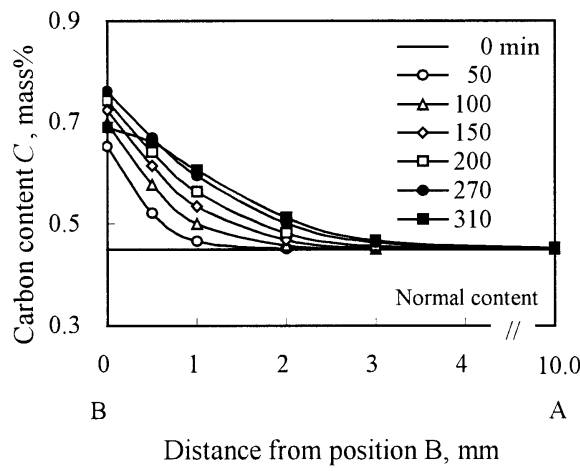

(b) Carbon content for carbonitrided quenching

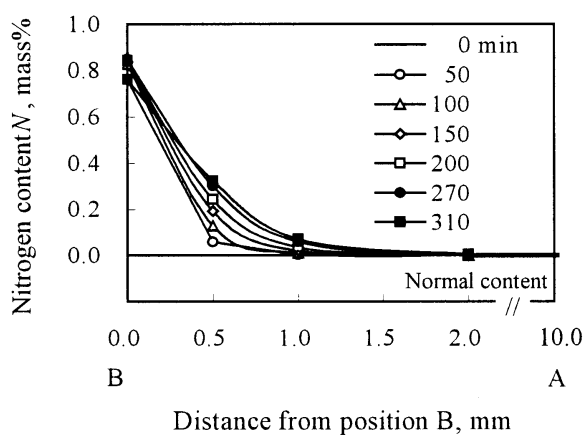

(c) Nitrogen content for carbonitrided quenching

Fig. 9. Predictions of carbon and nitrogen contents on the line $\mathrm{AB}$ corresponding to various treating times for carburized or carbonitrided quenching.

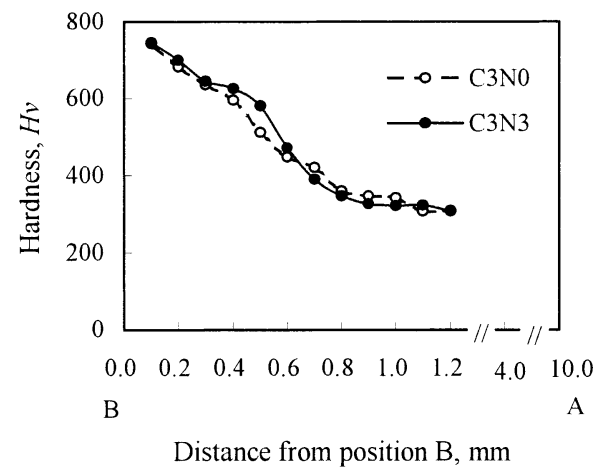

Fig. 10. Measured hardness values on the line AB. 


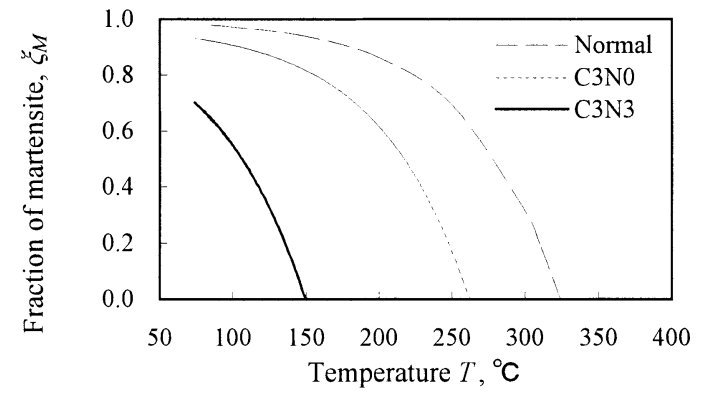

Fig. 11. Fraction of martensite phase versus temperature during quenching.

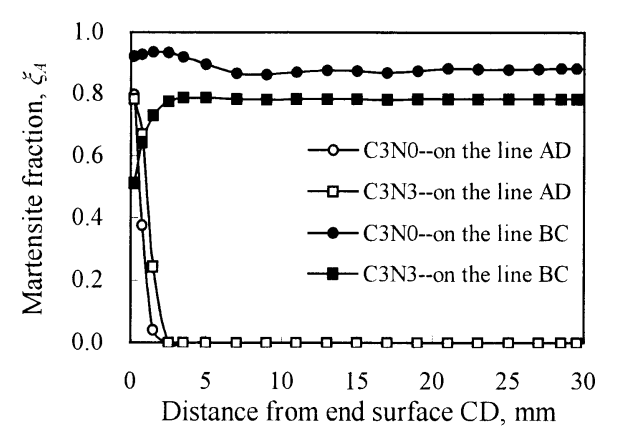

(a) Fraction of martensite phase

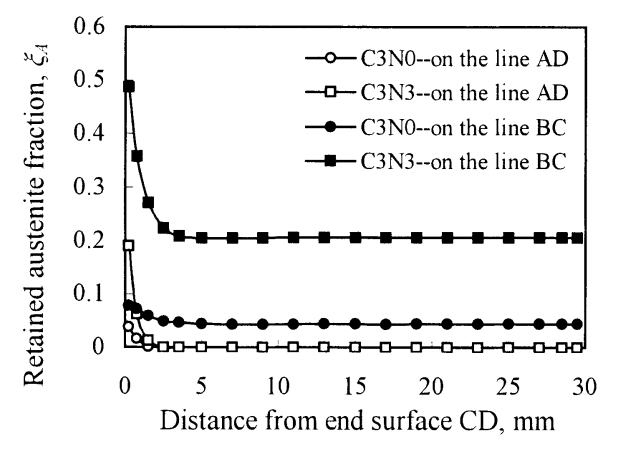

(b) Fraction of retained austenite phase

Fig. 12. Calculated fraction of microstructure on the lines AD and $\mathrm{BC}$.

quenching $(\mathrm{C} 3 \mathrm{~N} 3)$ occurs in the temperature ranges lower than that during quenching of $\mathrm{S} 45 \mathrm{C}$ with normal compositions (Normal). As is well known, the start temperature of martensite transformation due to higher carbon content is lower than that due to lower carbon content. Therefore, the volume fraction of martensite transformation and hardness increase along the radial direction incorporating with increasing of carbon contents from the center position A.

Figure 12 shows variations of the volume fraction of martensite (Fig. 12(a)) and austenite (Fig. 12(b)) on surface and center of the cylinder model. Although Fig. 12(a) shows that there is more martensite in this surface after carburized quenching than that after carbonitrided one, the hardening effect in the surface of the cylinder from carburized quenching $(\mathrm{C} 3 \mathrm{~N} 0)$ is almost identical to that from carbonitrided quenching $(\mathrm{C} 3 \mathrm{~N} 3)$, as shown in Fig. 10. Martensitic transformation during carbonitrided quenching occurs in lower temperature levels than during the carbur-

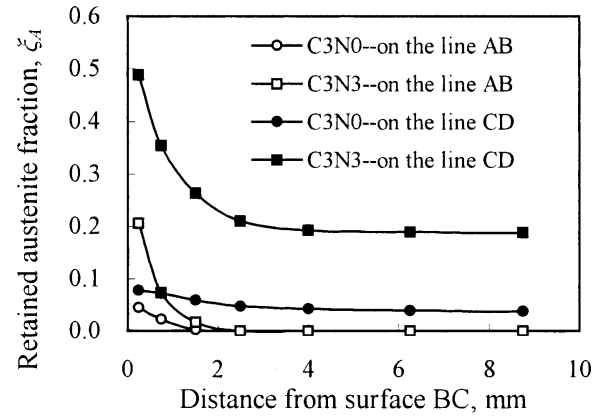

Fig. 13. Calculated fraction of retained austenite phase on the lines $\mathrm{AB}$ and $\mathrm{CD}$.

ized quenching (Fig. 11), which agrees with nitrogen and higher carbon contents (Fig. 8). According to the knowledge mentioned above, martensite formed in a lower temperature range is harder than that formed in higher temperature, ${ }^{23)}$ so the smaller fraction of martensite in the surface after carbonitrided quenching makes the same hardening effect as the more fraction of martensite formed in higher temperature after carburized quenching.

Similarly, the hardness values in the core AD for carburized quenching are almost the same those for carbonitrided quenching (Fig. 10). It may be resulted from almost the same microstructure (Fig. 12) and the same chemical compositions $(\mathrm{Fe}-0.45 \% \mathrm{C})$. In addition, Fig. 13 gives the retained austenite phase along radial direction on the middle section $\mathrm{AB}$ and on the end surface $\mathrm{CD}$. Because of more carbon and nitrogen contents, more austenite remained on the end surface CD. This kind of microstructure distribution has some effects on the distribution of residual stresses, which will be mentioned in next section.

\subsection{Stress Field and Distortion}

Metallo-thermo-mechanical calculations based on the data of $\mathrm{C}$ and $\mathrm{C} / \mathrm{N}$ profiles give the residual stresses after carburized quenching (C3N0) or carbonitrided quenching (C3N3). The calculated axial residual stress $\sigma_{Z}$ and tangential residual stress $\sigma_{\theta}$ on the middle section $\mathrm{AB}$ are shown in Fig. 14, and the calculated stresses, at least near the specimen surfaces, are found to be close to the measured axial residual stress $\sigma_{Z}$ and tangential residual stress $\sigma_{\theta}$ represented by solid square marks, which are measured by XRD. In the measuring of residual stresses, the X-ray tube was operated at $40 \mathrm{kV}$ and $40 \mathrm{~mA}$. The diffraction plane was the (211) of $\alpha \mathrm{Fe}$ phase and the diffraction angle $2 \theta$ was $156.4 \mathrm{deg}$. X-ray were counted for $30 \mathrm{~s}$ using a position sensitive proportional counter at angle of incidence $\psi_{0}$ ranging from 0 to $45 \mathrm{deg}$. The stress factor of the X-ray diffraction method was $-318.71 \mathrm{MPa} / \mathrm{deg}$. The residual stress was calculated by the $\sin ^{2} \psi$ method, i.e., the gradient of the line from the five points on the $2 \theta-\sin ^{2} \psi$ diagram using minimium square method.

Figure 15 displays the calculated axial and tangential stress distributions in the surface layer BC along axial direction. From these results, we can know that good agreements between the calculated and measured stresses after carbonitrided quenching are revealed, than but there is a larger difference between the calculated and measured residual stresses after carburized quenching. In Fig. 16, the tangential residual stress profiles in the end surface $\mathrm{CD}$ are 


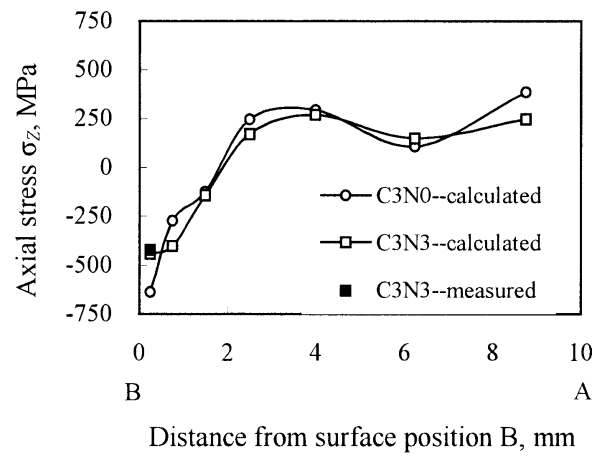

(a) Axial stress

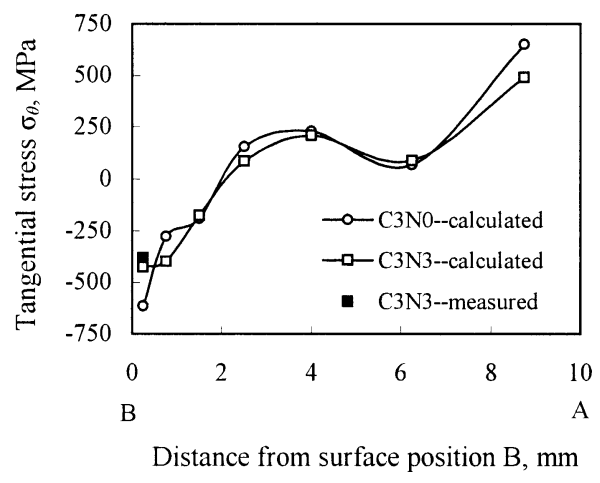

(b) Tangential stress

Fig. 14. Axial stress (a) and tangential stress (b) on the line AB.

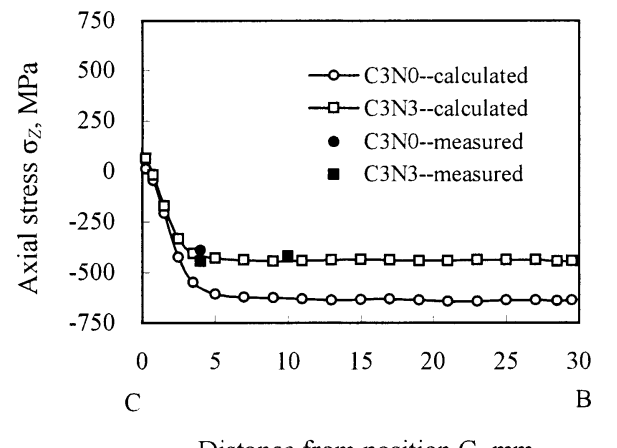

(a) Axial stress

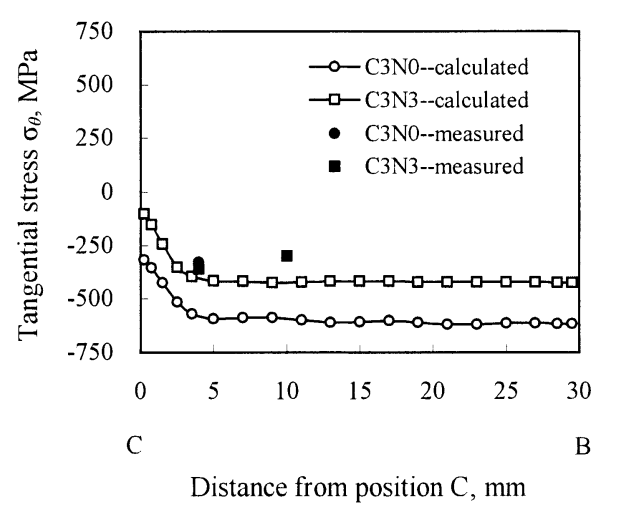

(b) Tangential stress

Fig. 15. Axial stress (a) and tangential stress (b) on the line BC.

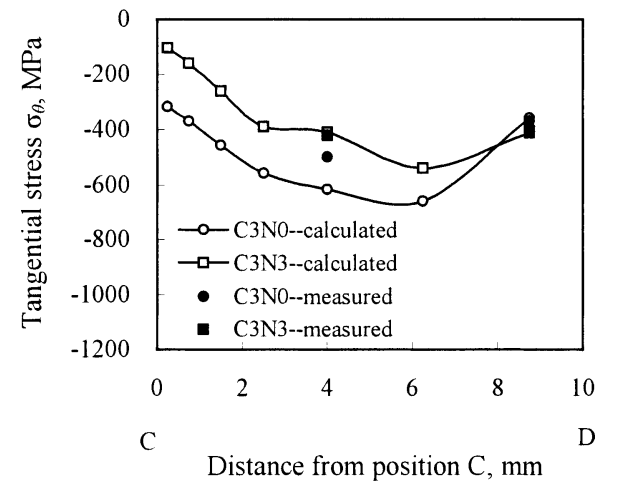

Fig. 16. Tangential stress on the line CD.

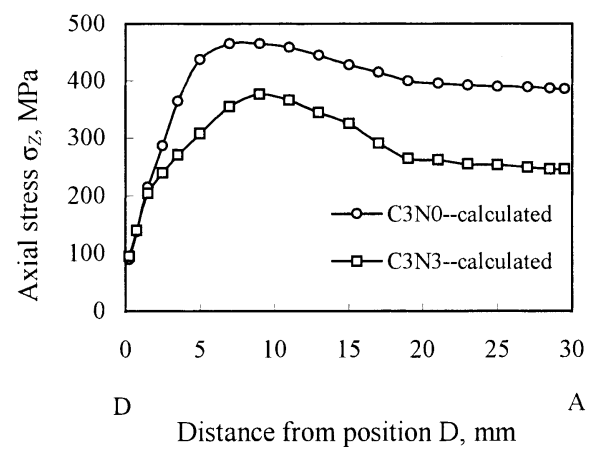

(a) Axial stress

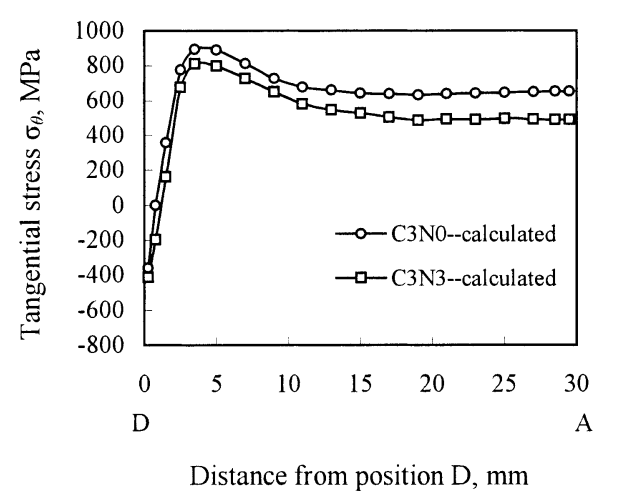

(b) Tangential stress

Fig. 17. Axial stress (a) and tangential stress (b) on the line DA.

demonstrated to agree well with the measured ones. The predicted profiles of axial and tangential stresses in the core AD along axial direction are also depicted in Fig. 17.

The generally good agreements between the calculated and measured stresses in Figs. 14 through 16 prove that the stress field calculation and the relevant numerical modeling used here are valid in predicting residual stresses.

As shown in Figs. 15 through 17, the stress values after carburized quenching are always larger than those after carbonitrided quenching, irrespective of any positions among surface $\mathrm{BC}$, end surface $\mathrm{CD}$ and core $\mathrm{AD}$. In addition, the residual tangential or axial stresses near the surface position $\mathrm{B}$ after carburized quenching are also larger than those after carbonitrided quenching (Fig. 14). A part of the reasons is ascribed to the difference in transformation volume fraction 


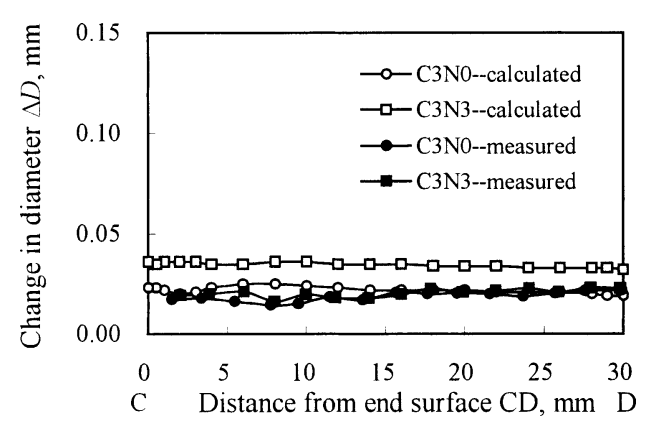

Fig. 18. The distortion after carburized quenching and carbonitrided quenching.

caused by the different carbon and nitrogen contents in these domains. As depicted in earlier section, higher carbon and nitrogen contents always decrease the volume fraction of austenite decomposed to pearlite or martensite and increase the volume fraction of retained austenite, as shown in Figs. 12 through 13. Higher volume fraction of decomposed austenite means more transformation expansion in the corresponding areas, thus larger transformation stresses are created. So the stresses in different areas have the distributions as shown in Figs. 14 through 17.

According to Fig. 14, the tangential or axial stresses in the depth range from $2 \mathrm{~mm}$ to the center after carburized quenching (C3N0) are almost identical to those after carbonitrided quenching (C3N3). The reason for this is that almost the same distribution of carbon and nitrogen contents (Fig. 9) in this depth range and identical external cooling conditions (Fig. 7) suggest the nearly identical microstructure variation and distribution there (Fig. 13), irrespective of carburized quenching or carbonitrided one. The similar phase transformation brings about similar transformation stress and also similar effect of transformation plasticity on stress field.

Furthermore, distortion after thermochemical processes is also concerned. Figure $\mathbf{1 8}$ observes the comparison of the calculated diametric changes with the measured ones, which represents that the calculated values are a little larger.

Whether stress or deformation is concerned, there are some deviations between the measured and calculated results. A part of the deviations may come from the neglect of the effects of carbon and nitrogen contents on constitutive equations since mechanical property parameters such as Young's modulus, yield strength, plastic modulus, thermal expansion coefficient and so on are lacked. In addition, transformation strain and transformation plasticity should be functions of carbon and nitrogen contents, but are assumed to be composition-independent at present due to the lack of quantitative data. Such kind of simplification may be another reason for the deviations above. Furthermore, though the calculated distributions of carbon/nitrogen and microstructure are harmonious with the measured and calculated results of hardness and stresses, verifications to the profiles of carbon and nitrogen contents and microstructure field are not performed at present. All these possible disadvantages need to be improved in near future by more experiments and adjustments of the calculation methods.

\section{Conclusions}

In this work, a finite element modeling was established on coupling analysis of the metallo-thermo-mechanical behavior as well as diffusion of carbon and nitrogen during carburized or carbonitrided quenching. Through numerical simulation of carburized or carbonitrided quenching, the effects of chemical compositions (carbon or nitrogen) on phase transformation and then hardness and residual stresses were reflected. Based on the comparisons between the calculated and measured results and on the discussions to the calculated results, the FEM modeling developed in this paper is proved to be effective in predicting diffusion of carbon/nitrogen, microstructure distribution, and stress/distortion fields during carburized or carbonitrided quenching. In addition, more work should be done for more accurate prediction of the metallo-thermo-mechanical behavior along with the diffusion of carbon or nitrogen in thermochemical-mechanical processing used in such specimens with complicated shape and thermal boundary conditions as gears and so on.

\section{Acknowledgements}

The authors wish to express their gratitude for the financial support by High-Tech-Research Center in Saitama Institute of Technology, Japan. Mr. H. Kamisugi and Mr. H. Hirano in Dowa Mining Co. Ltd. of Japan are also acknowledged for the cooperation during the experiments involved in this project.

\section{REFERENCES}

1) M. Kitamura, I. Tsukatani and T. Inoue: ISIJ Int., 34 (1994), 115.

2) E. J. Mittemeijer and M. A. J. Somers: Surf. Eng., 13 (1997), 483.

3) L. Torchane, P. Blilger, J. Dulcy and M. Gantois: Metall. Mater. Trans., 27A (1996), 1823.

4) F. Xinmin, S. Fei and H. Fei: Ordnance Mater. Sci. Eng., 22 (1999), 15.

5) G. H. Geiger and A. P. Poirier: Transport Phenomena in Metallurgy, Addison-Wesley, Reading, MA, (1981), 560.

6) H. Jimenez, M. H. Staia and E. S. Puchi: Surf. Coat. Technol., 120121 (1999), 358.

7) H. X. Ni, L. Y. Shan, C. Wang and Z. Y. Ni: Heat Treat. Met. (China), (1999), No. 6, 5.

8) Liu Cheng, A. Bottger and E. J. Mittemeijer: Metall. Trans., 23A (1992), 1129.

9) M. A. J. Somers, N. M. Vanderpers, D. Schalkoord and E. J. Mittemeijer: Metall. Trans., 20A (1989), 1533.

10) E. J. Mittemeijer and J. T. Slycke: Surf. Eng., 12 (1996), 152.

11) Liu Cheng, C. M. Brakman, B. M. Korevaar and E. J. Mittemeijer: Metall. Trans., 19A (1988), 2415.

12) B. J. Koo, M. A. J. Somers and E. J. Mittemeijer: Metall. Mater. Trans., 27A (1996), 1063.

13) A. Van Gent, F. C. Van Doorn and E. J. Mittemeijer: Metall. Trans., 16A (1985), 1371.

14) Y. Watanabe, K. Arata, N. Suzuki and Y. Mishima: Heat Treat. of Japan, 39 (1999), No. 2, 98.

15) S. Tsuji, I. Ishigami and K. Yamanaka: Trans. Jpn. Inst. Met., 28 (1987), 48

16) K. T. Raic: Surf. Coat. Technol., 92 (1997), 22.

17) Y. Sun and T. Bell: Mater. Sci. Eng. A, A224 (1997), 33.

18) L. Sproge and J. Ågren: J. Heat Treat., 6 (1988), 9.

19) J. G. Yang, M. Q. Zhao, K. W. Hu, J. Z. Chen and L. J. Yu: J. XI'AN Univ. Technol., 15 (1999), 1.

20) K. Bongartz, W. J. Quadakkers, R. Schulten and H. Nickel: Metall. Trans., 20A (1989), 1021.

21) S. Gut: Mater. Sci. Forum, 294-296 (1999), 565.

22) T. Inoue, D. Y. Ju and K. Arimoto: Proc. of Int. Conf. on Quenching 
and Control of Distortion, Vol. 1, ASM International, Materials Park, $\mathrm{OH},(1992), 205$.

23) C. Mgbokwere and M. Callabresi: J. Eng. Mater. Technol. (Trans. ASME), 122 (2000), 305.

24) D. Pont: Proc. of 3rd World Cong. on Computational Mechanics, IACM, Barcelona, (1994), 1723.

25) K. Arimoto, G. Li, A. Arvind and W. T. Wu: Proc. of the 18th ASM Heat Treating Process Conference \& Exposition, ASM International, Materials Park, OH, (1998), 121.

26) B. L. Ferguson, G. J. Petrus and A. M. Freborg: Mater. Sci. Eng., A245 (1998), 182.

27) T. Inoue, S. Nagaki, T. Kishino and M. Monkawa: Ing.-Archiv, 50 (1981), 315 .

28) M. A. J. Somers and E. J. Mittemeijer: Metall. Mater. Trans., 26A (1995), 57.

29) H. C. F. Rozendaal, E. J. Mittemeijer, P. F. Colijn and P. J. Vander Schaaf: Metall. Trans., 9A (1983), 395.

30) I. Ishigami, Y. Yokoyama, K. Miura, F. Uratani and H. Hoshino: $J$.
Soc. Mater. Sci. Japan, 49 (2000), 1235.

31) T. Inoue, T. Yamaguchi and Z. G. Wang: Mater. Sci. Technol., 1 (1985), 872.

32) D. Y. Ju, M. Narazaki, H. Kamisugi and H. Hirano: J. Shanghai Jiatong Univ., E-5 (2000), No. 1, 165.

33) C. L. Magee: Nucleation of Martensite, ASM, Materials Park, OH, (1968).

34) J. Kunze: Steel Res., 57 (1986), 361.

35) M. A. J. Somers and E. J. Mittemeijer: Surf. Eng., 3 (1987), 123.

36) L. Maldzinski, W. Liliental, G. Tymowski and J. Tacikowski: Surf. Eng., 15 (1999), 377.

37) A. Bjarbo and M. Hattestrand: Metall. Mater. Trans., 32A (2001), 19.

38) L. Cheng, A. Bottger, T. H. Keijser and E. J. Mittemeijer: Scr. Metall. Mater, 24 (1990), 509.

39) D. Ruan, J. S. Pan, W. M. Zhang and M. J. Hu: Heat Treat. Met. (China), (1999), No. 7, 15. 